\title{
Comércio em fronteira: os circuitos da economia urbana em Guajará-Mirim (Estado de Rondônia, Brasil) e Guayaramerín (Departamento de Beni, Bolívia)
}

\author{
Border trade: the urban economy circuits in \\ Guajará-Mirim (State of Rondônia, Brazil) and Guayaramerín \\ (Beni Department, Bolívia)
}

Comercio fronterizo: los circuitos de economía urbana en Guajará-Mirim (Estado de Rondônia, Brasil) y Guayaramerín (Departamento de Beni, Bolivia)

Thiago Oliveira Neto ${ }^{l}$ Universidade Federal do Amazonas, Brasil Ricardo José Batista Nogueira ${ }^{2}$ Universidade Federal do Amazonas, Brasil Carlos Eduardo Silva Simões Rafael ${ }^{3}$ Universidade Federal do Amazonas, Brasil Yuji Santos Yano ${ }^{4}$ Universidade Federal do Amazonas, Brasil

1 Graduado em Geografia e Mestre em Geografia ambos pela Universidade Federal do Amazonas-UFAM, doutorando em geografia humana pela Universidade de São Paulo-USP, Brasil.

(iD https://orcid.org/0000-0003-2877-3606. E-mail: thiagoton91@live.com

2 Graduado em Geografia e Administração pela Universidade Federal do Amazonas-UFAM, Mestre e Doutor em geografia humana pela Universidade de São Paulo-USP, professor titular do departamento de geografia da UFAM. E-mail: nogueiraricardo@uol.com. (D) https://orcid.org/0000-0002-7217-2237

3 Graduando em Licenciatura em Geografia pela Universidade Federal do Amazonas-UFAM, realizou no ano de 2019 mobilidade acadêmica para Universidade de Brasília-UNB,

e-mail: eduardo.simoes.rafael@gmail.com (D) https://orcid.org/0000-0002-2845-6347

4 Graduado em Bacharelado em Geografia pela Universidade Federal do Amazonas-UFAM, mestrando em Geografia pela mesma universidade, graduando em Direito pelo Ciesa. E-mail: yuji.yano@hotmail.com. (iD https://orcid.org/0000-0002-4498-3083 
Thiago Oliveira Neto, Ricardo José Batista Nogueira, Carlos Eduardo Silva Simões Rafael, Yuji Santos Yano Comércio em fronteira: os circuitos da economia urbana em Guajará-Mirim (Estado de Rondônia, Brasil) e Guayaramerín (Departamento de Beni, Bolívia)

\begin{abstract}
Resumo
O comércio na fronteira é constituído pelos fluxos e pelos objetos fixados nas cidades ou ao longo das vias de circulação, o que cria uma dinâmica constituída em diversos níveis de modalidade de comércios, que vão desde a presença de lojas que fazem parte de alguma "rede", galpões até o comércio informal. Para elucidar o caso particular da fronteira Brasil-Bolívia nas cidades de GuajaráMirim e Guayaramerín, optamos em utilizar como marco teórico a proposta de Santos (1979; 2004) dos circuitos da economia urbana.
\end{abstract}

Palavras chave: comércio, fronteira, circulação.

\begin{abstract}
Border commerce is comprised of fluxes and fixed objects within cities or along circulation routes, which creates dynamism based on the different levels of commerce ranging from the presence of "chain" stores and retail outlets, small-store sheds to informal commerce. To elucidate the particular case of the Brazil-Bolivia border cities of Guajará-Mirim and Guayaramerín, we chose to use Santos's $(1979 ; 2004)$ proposal of urban economy circuits as the theoretical framework.
\end{abstract}

Keywords: Trade; Border; Circulation.

\title{
Resumen
}

El comercio fronterizo está compuesto por flujos y objetos fijos dentro de las ciudades o a lo largo de rutas de circulación, esto crea una dinámica basada en diferentes niveles de modalidades de comercio, que van desde la presencia de almacenes o mercados que forman parte de alguna "cadena", pequeñas tiendas (galpones) hasta el comercio informal. Para dilucidar el caso particular de las ciudades fronterizas de Guajará-Mirim y Guayaramerín, en la frontera entre Brasil y Bolivia, escogimos como marco teórico la propuesta de Santos $(1979 ; 2004)$ para los circuitos de la economía urbana.

Palabras clave: Comercio; Frontera; Circulación.

\section{Introdução}

A circulação do fluxo comercial nas fronteiras ocorre interdependente da existência da conexão terrestre ou fluvial e o deslocamento de pessoas e de veículos entre cidades fronteiriças transportando cargas e bens de consumo, ora são para satisfazer a necessidade básica individual ora para recomercializar no outro país.

As cidades situadas na fronteira possuem o papel relevante do ponto de vista econômico e da circulação de pessoas e de mercadorias, pois são os pontos mais avançados da soberania do país no contexto de integração regional. Os núcleos urbanos e o conjunto dos sistemas de engenharia assumem o papel não mais centrados na fiscalização, contenção e 
Thiago Oliveira Neto, Ricardo José Batista Nogueira, Carlos Eduardo Silva Simões Rafael, Yuji Santos Yano Comércio em fronteira: os circuitos da economia urbana em Guajará-Mirim (Estado de Rondônia, Brasil) e Guayaramerín (Departamento de Beni, Bolívia)

de separar o "meu do seu", mas passam a assumir a feição de uma efetiva integração regional.

Nesse contexto, as cidades fronteiriças de Guajará-Mirim no Brasil e Guayaramerín na Bolívia têm como aspecto central a ligação terrestre entre os centros dinâmicos e políticos dos respectivos países até a fronteira e com essa rede, o que inclui a navegação fluvial e propicia os fluxos entre as cidades e o estabelecimento de interações espaciais.

Para realização da pesquisa optou-se em uma estrutura metodológica constituída em 3 etapas: primeiramente houve as leituras de livros, artigos, teses e dissertações de mestrado que abordam os temas relacionados a fronteira, comércio, circuito da economia urbana e Amazônia; em um segundo momento foi realizado um trabalho em campo ${ }^{6}$ nas cidades de Guajará Mirim e Guayaramerín no mês de julho de 2019, que teve o propósito de verificar e de compreender a dinâmica da fronteira, centrando atenção para a circulação e transportes de pessoas e de cargas, presença de instituições do Estado e o comércio; por fim, a terceira parte, consistiu na sistematização e redação do trabalho com base nas observações e informações obtidas por meio de entrevistas abertas com instituições do Estado e no comércio local.

Para elucidar a discussão sobre o comércio na fronteira, optamos em fazer uma abordagem sobre fronteira com base nas abordagens de Benedetti (2014); na segunda parte aborda-se uma compreensão dos circuitos econômicos na fronteira com base na teoria do espaço dividido de Milton Santos.

\section{Fronteira: organização espacial}

Silva (2013, S/P) aponta que as cidades situadas na fronteira brasileira assumem o papel relevante no século XXI, pois estes núcleos urbanos são "os pontos mais avançados da soberania deste país no contexto de cooperação e da integração regional” principalmente do ponto de vista da economia e da circulação de mercadorias e de pessoas, no entanto, o mesmo autor ainda pontua que diversos problemas encontram-se inseridos no espaço de fronteira e que compromete uma dada inserção transfronteiriça

\footnotetext{
5 "Muito embora a função de Guajará-Mirim no seu surgimento tenha sido associada à defesa territorial em relação ao povoado que surgira no lado boliviano no caso o município de Guayaramerín" (Lira, 2017, p. 121).

6 Financiamento do Conselho Nacional de Pesquisa e Desenvolvimento tecnológico- CNPQ.
} 
Thiago Oliveira Neto, Ricardo José Batista Nogueira, Carlos Eduardo Silva Simões Rafael, Yuji Santos Yano Comércio em fronteira: os circuitos da economia urbana em Guajará-Mirim (Estado de Rondônia, Brasil) e Guayaramerín (Departamento de Beni, Bolivia)

que alcance o desenvolvimento econômico e social, como por exemplo: contrabando, roubo de veículos, passagem de drogas, prostituição, garimpo ilegal e desvio de usos normativos.

A funcionalidade da fronteira deixou de ser um espaço de separação para ser um espaço fronteiriço de integração, talvez esteja aí a principal diferença da compreensão clássica da geopolítica sobre fronteira para a atual, onde os processos atuais empenhados ora pelos Estados e pela economia transformaram as fronteiras, além disso, o espaço de fronteira é um espaço vivido com diversas relações sociais e interações espaciais que envolvem as cidades e povos dentro de um cotidiano cultural, social e econômico.

Com base em Moraes, podemos afirmar que ao mesmo tempo que o território é constituído de três construções militar-jurídica-ideológica (2000), a fronteira também perpassa por essa tríade, que pode ser representada pela participação e presença das forças armadas; as ações na fronteira estão vinculadas a uma legislação em face aos preceitos do direito vigente; e a difusão do sentimento de pertencimento da população.

A fronteira pode apresentar arranjos espaciais de forma distintas (figura 1), sendo duas cidades com contiguidade espacial entre ambas, cidades com descontiguidade espacial seja por um rio ou pela sua própria formação que ocorreu com um distanciamento entre ambas, cidade interligada por rodovia, cidade interligada por ponte, e cidade interligada pela navegação sem ponte.

A fronteira possui um padrão de organização espacial que pode ser constituído pelos sistemas de engenharia (figura 1) que possibilitam fluxos, sejam nas rodovias, pontes, portos e aeroportos. Outros objetos como aviões, embarcações, automóveis, ônibus e caminhões fazem parte da dinâmica dos fluxos que ocorrem na fronteira e entre esta com as cidades dos países. Além desses atributos técnicos, tem-se a presença do comércio estabelecido de forma itinerante, em lojas, em barracas e sem estrutura fixa muita das vezes e estando nas proximidades dos portos e rodovias.

$\mathrm{Na}$ figura 1 podemos identificar os diferentes tipos de fronteira entre as cidades brasileiras e de alguns países representados, chamando atenção para os sistemas de engenharia que permitem a ligação material entre as cidades, que apesar de terem esses objetos como ponte e rodovias, às vezes a integração pelos fluxos se completa pelos deslocamentos fluviais como é o caso da fronteira Brasil e Guiana Francesa. 
Thiago Oliveira Neto, Ricardo José Batista Nogueira, Carlos Eduardo Silva Simões Rafael, Yuji Santos Yano Comércio em fronteira: os circuitos da economia urbana em Guajará-Mirim (Estado de Rondônia, Brasil) e Guayaramerín (Departamento de Beni, Bolívia)

Figura 1. Arranjo espaciais na fronteira. Org. Thiago O. Neto.
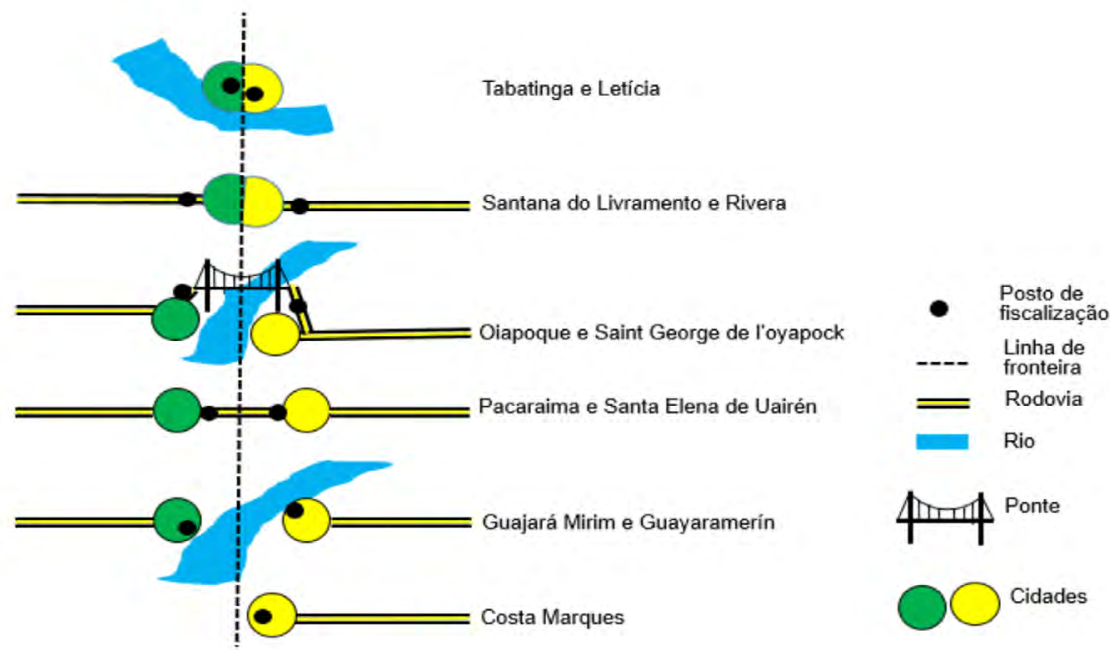

A fronteira entre o Brasil e a Bolívia, mais precisamente entre as cidades de Guajará-Mirim -Brasil- e Guayaramerín -Bolívia, possui a característica de ter o rio Mamoré ${ }^{7}$ como elemento natural que separa as duas cidades e que corresponde a fronteira (figura 2).

Silva e Diniz (2019, p. 179) apontam que as conexões viárias conseguem estabelecer um papel nas intensificações dos fluxos e a ausência de uma ponte entre as duas cidades "não impediu o estabelecimento de relações simbióticas em determinados planos das relações internacionais", pois "as forças de conexão entre as comunidades brasileiras e bolivianas lindeiras mostraram-se mais poderosas do que os obstáculos impostos pela natureza e a carência de investimentos nos transportes".

A cidade de Guajará-Mirim estima-s 46 mil habitantes (Ibge, 2019a), enquanto a cidade de Guayaramerín possui 46 mil habitantes (Ine, 2016), além de ter outras cidades como Nova Mamoré com 30 mil habitantes estando a 48km da fronteira (Ibge, 2019b), e na Bolívia a cidade de Riberalta

7 O rio Mamoré possui 1.930 quilômetros, nasce na Bolívia e sua foz é no rio Madeira, em território brasileiro. "Os portos de Guajará-Mirim e Guayaramerín intermediam as experiências de convívio binacional, proporcionando a travessia do rio Mamoré. As travessias são organizadas por empresas que seguem uma padronização quanto ao tipo de embarcação e medidas de segurança" (Silva; Diniz, 2019, p. 198). 
Figura 2. Cidades na fronteira.

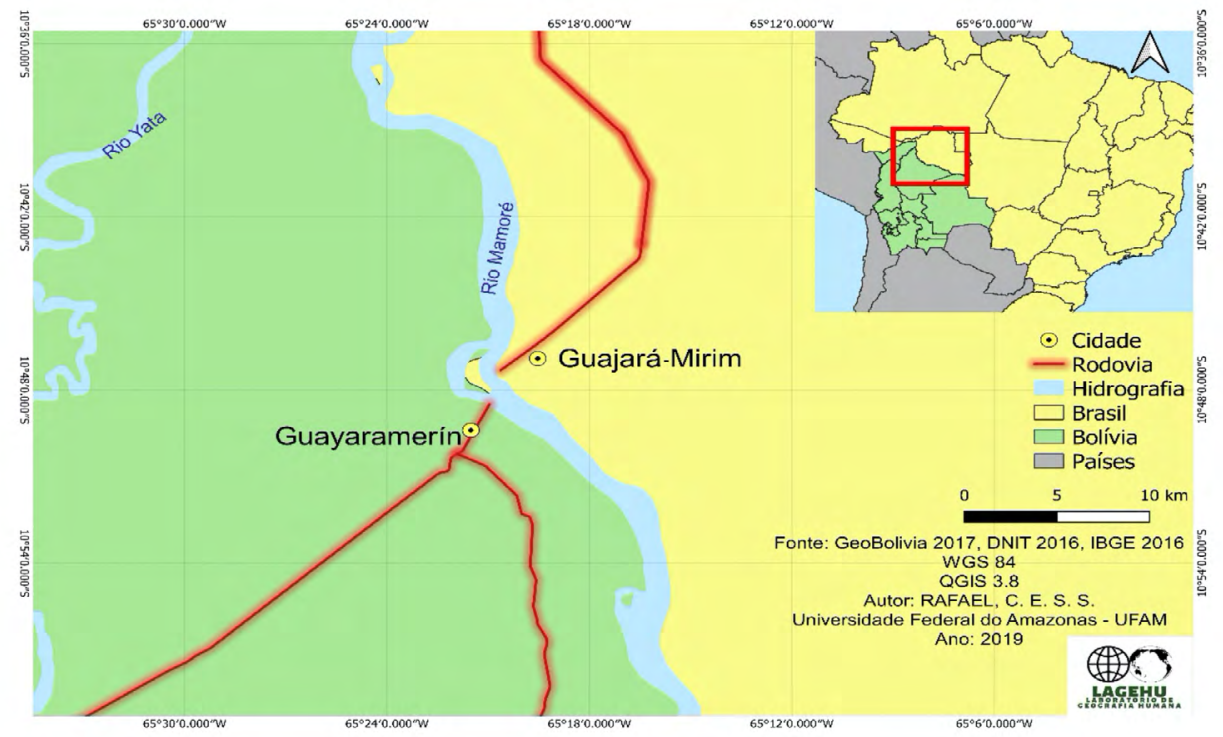

com 96 mil habitantes a 90km da fronteira (Ine, 2016). Ou seja, frações territoriais com cidades e com dinâmicas urbanas entre as mesmas.

A construção da ferrovia, no início do século XX, resultado de um acordo fronteiriço para escoar a produção de borracha da Bolívia, permitiu ligar as cidades de Porto Velho e Guajará-Mirim contornando os rios Madeira e Mamoré, visto que estes não permitiam a navegação com o transporte de carga e de passageiros. A primazia dos fluxos ferroviários se estabeleceu entre 1912 até 10 de julho de 1972 quando teve sua última viagem e as rodovias BR-364 e BR-425 já estavam construídas ${ }^{8}$.

A falta de investimentos e o sistema ferroviário envelhecido passou a acumular ineficiências com o aumento no tempo de deslocamento e com a instalação de um outro sistema de engenharia, como as rodovias que visavam tornar mais eficientes os movimentos regionais entre as cidades, algo que ocorreu somente quando houve a conclusão total da pavimentação da rodovia BR-425 na década de 80 .

8 O deslocamento das maquinas para a construção da rodovia BR-425 conto com o transporte dos equipamentos pela ferrovia. 
Na proposta de Benedetti compreende-se a fronteira como um espaço fronteiriço em seis componentes básicos: diferenciação territorial, fronteirização, territórios subnacionais e interiores, territórios exteriores, lugares de fronteira (figura 3) e mobilidades (2014).

Figura 3. Lugares fronteiriços.

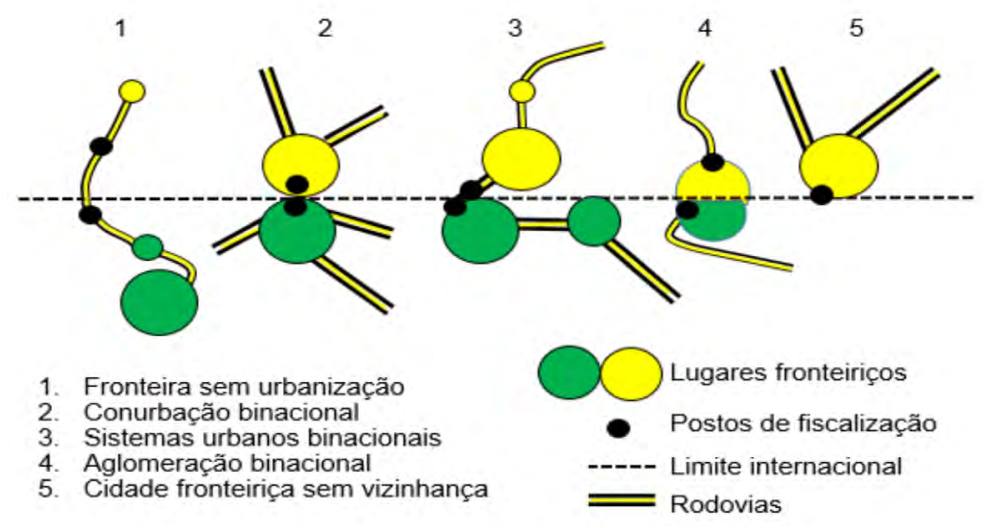

Adaptado de Benedetti (2014).

Existem formas peculiares de arranjos espaciais das fronteiras, onde essas formas especificas são singulares de uma dada formação do território, logo encontra-se aí a diferenciação regional que está cabalmente lado a lado da fronteira, onde tem em cada país, ou fração territorial de um Estado, uma dada organização política, social, econômica e cultural.

Existe uma interação espacial entre as cidades de Guajará-Mirim, Nova Mamoré, Porto Velho etc., e Guayaramerín, Riberalta, Trinidad, Cobija etc., no entanto não se constitui em um sistema urbano binacional em nenhuma das margens da fronteira, pois não ocorre o processo de conurbação, mas fluxos de veículos que perpassam esses lugares e o deslocamento das pessoas para as cidades de fronteira para fins de comércio ou de atendimento à saúde.

A descontiguidade espacial das cidades em decorrência da existência do rio Mamoré, forma o que Benedetti denominou de conurbação binacional, descrita como lugares de fronteira denominadas de cidades gêmeas, sendo constituída de pares de cidades e que constituem em lugares de 
compra (2014), que no caso particular ocorre de forma mútua, brasileiros compram na cidade boliviana e bolivianos compram na cidade brasileira.

Para Benedetti, a fronteira e a mobilidade são aspectos indissociáveis (2014), e partimos desse mesmo apontamento, em que os fluxos diversos na fronteira são um dos aspectos que permitem a compreensão da dinâmica fronteiriça.

O padrão radial (figura 4a) que Benedetti aponta consiste quando uma grande cidade se localiza no espaço de fronteira, centralizando fluxos e com diversos caminhos que interliga outras cidades (2014). No caso especifico das cidades de Guajará-Mirim e de Guayaramerín, esse padrão (figura 4b) é formado pelas cidades de maior porte interligadas com o espaço de fronteira por rodovias.

Figura 4. Padrão radial na fronteira; a) modelo de Benedetti (2014); b) modelo da fronteira Brasil-Bolívia. Org. Thiago O. Neto.
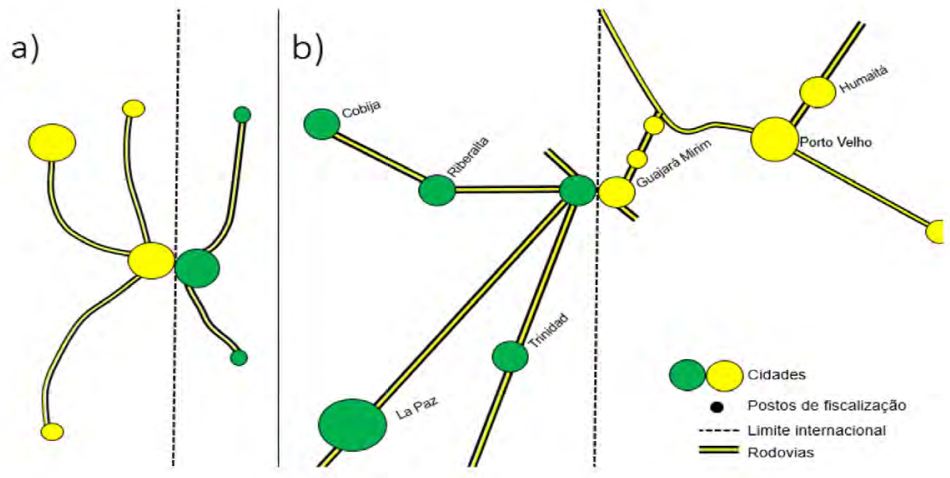

As multiplicidades de arranjos espaciais da circulação na fronteira podem ser constituídas em distintas redes que se estabelecem, como aponta o modelo de Benedetti (2014) o qual apresenta uma classificação e identificação dos tipos de trajetos existentes na fronteira, o que denominamos de arranjo espacial.

Os tipos de espaço de fronteira apontados por Benedetti (2014), centram-se em oito (figura 5): urbanas nacionais - onde as populações desenvolvem suas atividades e a circulação ocorre dentro de uma cidade; urbanas binacionais - ligação com fluxos entre as duas cidades que 
estão engendradas pelos laços de parentescos, religiosas, desportivas etc.; fronteiras unilaterais - constituída por cidades que podem "gravitar" nas áreas próximas ao distrito fronteiriço; fronteirização bilateral - são constituídos pelos fluxos que ocorrem somente de um lado da fronteira e entre cidades de um mesmo país e que ocorrem em ambos os lado da fronteira; interiores - formado pelos pontos de verificação/fiscalização; translimítrofes - ocorre pelos fluxos que transcendem de uma cidade de fronteira para outra em decorrência da própria assimetria entre os países; transfronteiriço nacional - zona de circulação entre lugares interiores do país com deslocamentos que perpassam pela fronteira; transfronteiriço binacional - relações espaciais que perpassam as cidades fronteiriças sem ter o termino ou o início nas respectivas cidades.

A cidade de fronteira enquanto centralidade de diversas formas espaciais urbanas, consegue abrigar um conjunto de interações espaciais que se articulam para além da área urbana, e no caso da cidade de fronteira, o alcance da articulação ocorre entre os países com deslocamentos do cotidiano (figura 5).

Figura 5. Tipos de fluxos entre as cidades em círculos verde e amarelos.

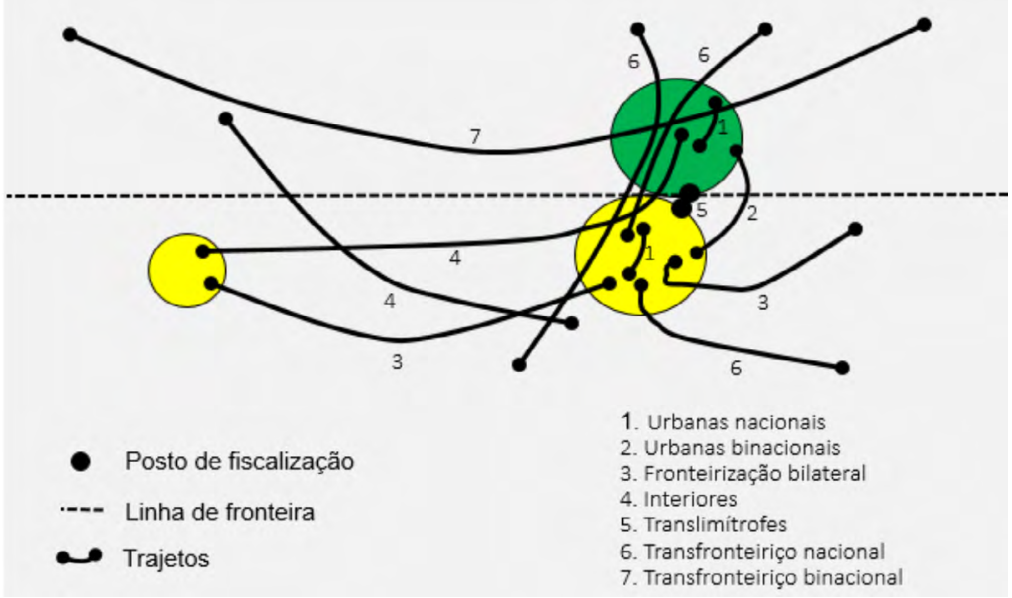

Adaptado de Benedetti (2014).

Silva e Diniz (2019, p. 177) apontam que "as cidades-gêmeas constituem-se como pontos nevrálgicos das mais diversas redes sobrepostas, sendo a sua posição geográfica um dos seus maiores trunfos”. 
Uma das dinâmicas de mobilidade da fronteira é constituída pelos fluxos entre as cidades cruzando a linha de fronteira, o que "não implica em mudança de residência, mas em deslocamentos para realizar atividades específicas como compras, lazer etc.” (Lira, 2017, p. 119) e essa circulação é uma das características da porosidade da fronteira que é resultante da existência da diferenciação regional, formação socioespacial distinta, cidades, atividades comerciais e serviços existentes.

Os fluxos dos "indivíduos que transitam pela fronteira com alguma regularidade mostrando que o ir e vir pela fronteira, no caso entre as cidades gêmeas, se torna uma atividade essencial e complementar no "espaço de vida" daqueles que ali residem" (Lira, 2017, p. 121).

As cidades fronteiriças de Guajará-Mirim e Guayaramerín também possuem essas características, obviamente que o excepcionalismo está centrado no conteúdo dos fluxos entre as cidades por meio das redes no espaço de fronteira, que possui elementos diversos como os sistemas de engenharia fixos e as rodovias que possibilitam os fluxos (figura 6); sistemas de transporte entre as cidades etc.

Figura 6. Fluxos entre as cidades.

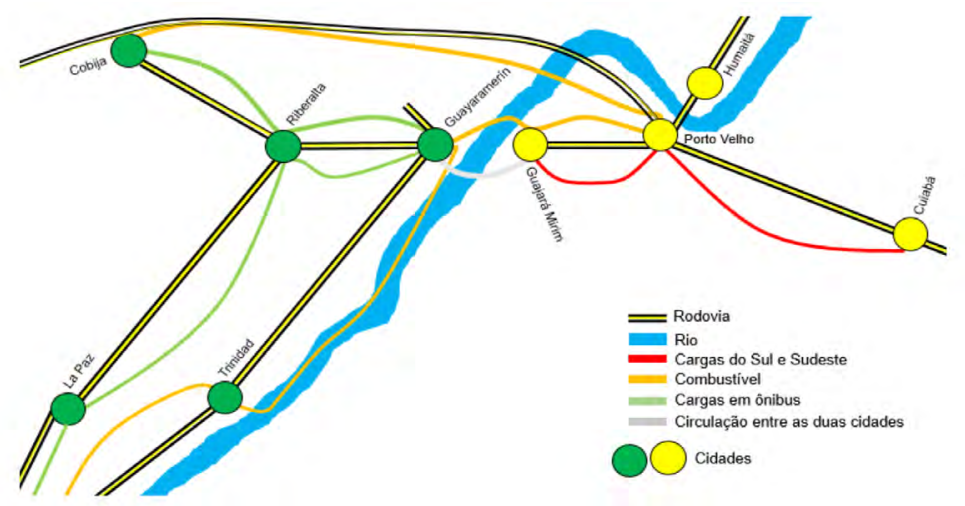

Org. Thiago O. Neto.

As cidades de fronteira representam um nó de uma rede de circulação, seja como ponto final da via de acesso ou pela centralidade criada pelos serviços e pelos fluxos convergentes a esta. No caso particular, a fronteira é formada por dois nós, um na cidade de Guajará-Mirim e outro em Guayaramerín. 
Thiago Oliveira Neto, Ricardo José Batista Nogueira, Carlos Eduardo Silva Simões Rafael, Yuji Santos Yano Comércio em fronteira: os circuitos da economia urbana em Guajará-Mirim (Estado de Rondônia, Brasil) e Guayaramerín (Departamento de Beni, Bolívia)

Apesar dos limites rígidos da fronteira, as relações de comércio perpassam esses limites onde se estabelece distintas formas para a comercialização na fronteira. Nesse sentido, podemos destacar os distintos fluxos de passageiros e de cargas entre as cidades (figura 7).

Figura 7. Porto de Guajará-Mirim: a) carretas com cargas para exportação; b) carreta com carga para exportação; c) transbordo de carga dos caminhões para as lanchas/batelões; d) margem direita do rio Mamoré onde se realiza o embarque e desembarque das cargas.

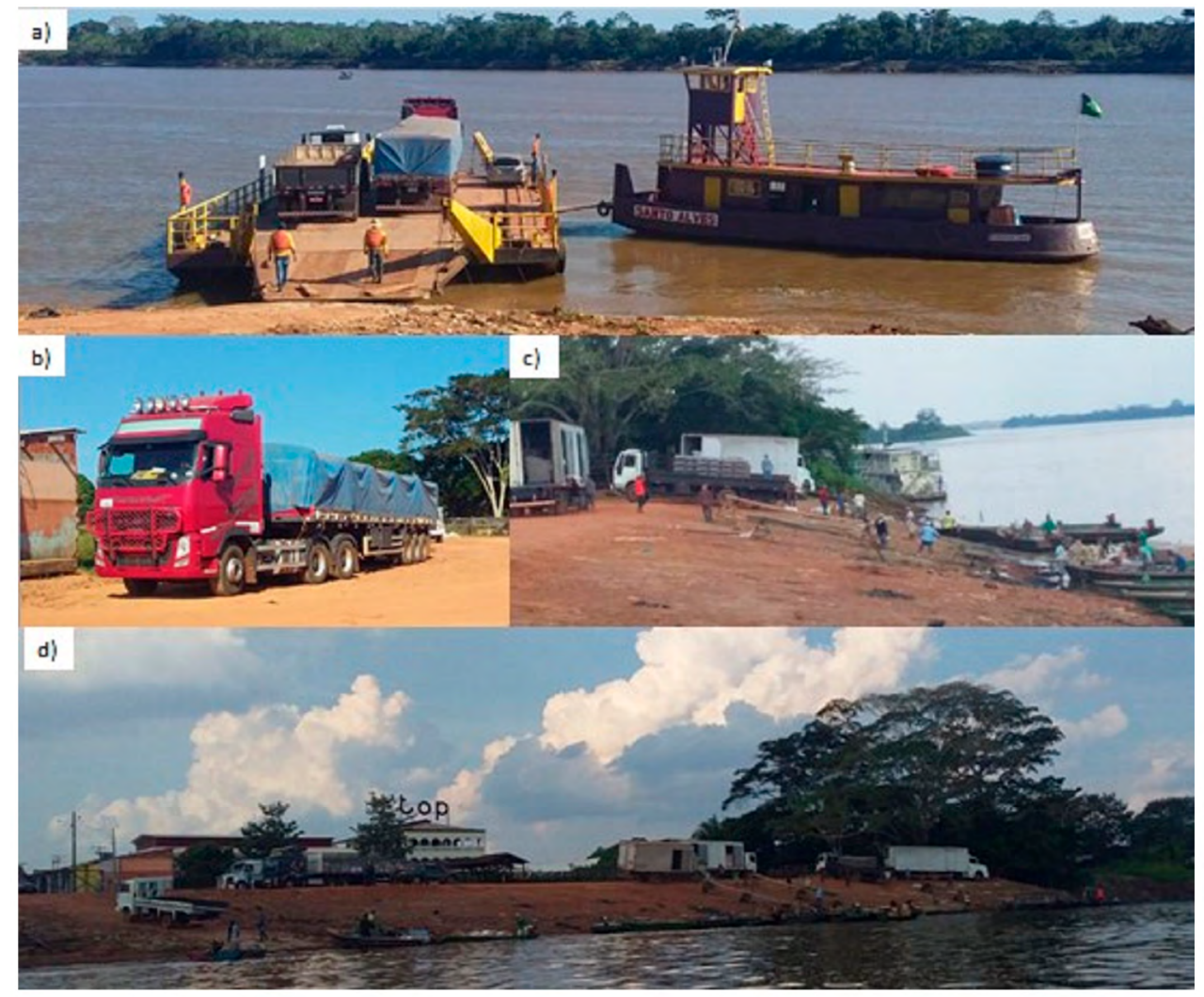

Org. Thiago O. Neto. 
Thiago Oliveira Neto, Ricardo José Batista Nogueira, Carlos Eduardo Silva Simões Rafael, Yuji Santos Yano Comércio em fronteira: os circuitos da economia urbana em Guajará-Mirim (Estado de Rondônia, Brasil) e Guayaramerín (Departamento de Beni, Bolívia)

\section{Circuitos da economia urbana na fronteira Brasil-Bolívia}

A circulação de bens, de produtos acabados, ocorre substancialmente pela existência de fixos como as rodovias e a aglomeração humana que consome parte dos produtos encaminhados para a fronteira.

As trocas realizadas na fronteira constituídas em compras e produtos é recorrente tanto de um quanto do outro lado da fronteira, onde as principais necessidades cotidianas se satisfazem com o que se oferece no mercado local (Benedetti; Salizzi, 2011). Lira, em um estudo sobre fronteira, aponta que "as cidades gêmeas possuem destaque pela importância das trocas comerciais, de bens e serviço entre si e com influências que vão além dos seus limites municipais" (2017, p. 130).

Para compreender as interações espaciais que estão centradas no comércio, optamos em utilizar a divisão de circuito superior e inferior da economia urbana (Santos, 1979; 2004) para compreender o caso da fronteira em questão, que precisa de alguns ajustes e adaptações para as mudanças gerais e para as excepcionalidades do lugar, assim como o uso de técnicas informacionais que acarretam possíveis problemas para aplicar diretamente da teoria sem breves ponderações e adaptações. Nesse sentido, vamos agrupar dois grandes grupos: o circuito das empresas apresenta sede situada noutro lugar que não é a fronteira, presença de galpões para armazenamento e transbordo de cargas com o uso de empilhadeiras, possibilidade de acesso a crédito e incentivos fiscais de agência governamentais, inclui-se ainda, a rede bancária, transportadoras com frotas de caminhões; o circuito dos comércios engloba todos os estabelecimentos comerciais que possuem sede em Guajará-Mirim e são constituídos de pequenos objetos geográficos que correspondem a extensão de uma parte da residência e a transformada em comércio, ou ainda, em lojas e comerciantes das feiras e que vendem bens de consumo, alimentando a dinâmica social e urbana.

A partir desses dois circuitos -empresas/superior e comércios/inferior- se estabelecem os fluxos que fazem parte das interações espaciais com fluxos de pessoas, cargas e informações entre as cidades.

As empresas impõem um arranjo funcional e organizacional com "um objetivo comum - a acumulação de capital-, mesmo que cada agente tenha sua própria maneira de operar" (Santos, 1979, p. 30) em uma ação coordenada que articula cidades onde foram produzidos os bens de 
Thiago Oliveira Neto, Ricardo José Batista Nogueira, Carlos Eduardo Silva Simões Rafael, Yuji Santos Yano Comércio em fronteira: os circuitos da economia urbana em Guajará-Mirim (Estado de Rondônia, Brasil) e Guayaramerín (Departamento de Beni, Bolívia)

consumo, a cidade de fronteira e as demais cidades para onde as mercadorias são reencaminhadas.

Para Santos "a função regional das cidades regionais declina porque a revolução dos transportes torna possível que as pequenas cidades tenham relações diretas com as cidades maiores, inclusive com as metrópoles" (1979, p. 32), e tal processo está presente em Rondônia, com a ligação das cidades com o sistema viário nacional.

A proposta apresentada por Santos aponta a "existência (...) de dois sistemas de fluxo econômico, cada um sendo um subsistema do sistema global que a cidade em si representa" (1979, p. 128). A gênese da formação desses circuitos, para Santos, estaria centrada na existência de uma massa populacional com salários muito baixos e que depende de trabalho ocasional para obter recursos, tendo ainda, uma outra massa bem menor, com altos salários, criando uma sociedade urbana com diferenciações de acesso aos bens de consumo e serviços, o que causa a existência de "de dois sistemas de fluxos que afetam a fabricação, a distribuição e o consumo de bens e serviços" (Santos, 1979, p. 130).

O circuito superior" da economia urbana seria "composto de negócios bancários, comércio de exportação e indústria de exportação, indústria urbana moderna, comércio moderno, serviços modernos, comércio atacadista e transportes", enquanto que o circuito inferior aglutinaria atividades que possuem "formas de fabricação de capital não intensivo, por serviços não modernos, geralmente abastecidos pelo nível de venda a varejo e elo comércio em pequena escala e não moderno" (Santos, 1979, p. 132).

O mesmo autor ainda aponta a existência de diferenciações dentro do circuito superior: atividades puras representadas pelas moderna indústria urbana, o comércio e os serviços modernos atividades urbanas e do sistema superior; atividades impuras: formadas pelo comércio de exportação, "enquanto elas podem ser estabelecidas na cidade, para se beneficiar das vantagens locacionais", incluindo "os negócios bancários podem ser incluídos nessa categoria, visto que funcionam como um elo entre as atividades modernas da cidade e as grandes cidades dentro do país e exterior"; atividades mistas: referente às vendas por atacado, transportes "ambas tem laços funcionais tanto com o sistema de fluxos superior quanto com o inferior da economia urbana e regional" (Santos, 1979, p. 132).

9 Para Santos “o circuito superior originou-se diretamente da modernização tecnológica" (2004, p. 22). 
No circuito das empresas, esse conjunto dos três tipos de atividades são identificadas na cidade de Guajará-Mirim: atividades puras são constituídas pela presença de atacadistas, concessionária de automóveis, lojas que integram grandes redes como a Top Internacional, especializada em perfumes e bebidas, com várias lojas pelo país; as atividades impuras são constituídas pela participação dos atacadistas e demais empresas responsáveis pela exportação de bens de consumo e a presença da rede bancária; e por fim, as atividades mistas são formadas pela presença de lojas que realizam a venda por atacado para a população que mora em Guajará-Mirim e Guayaramerín e a atividade de transporte de carga e de passageiros, primeiramente o deslocamento de cargas do interior do país para a fronteira, que ocorre tanto com o uso de caminhões quanto nos ônibus, este último principalmente entre as cidades bolivianas até Guayaramerín.

O papel das vendas em atacado se constituem no cume e são responsáveis por alimentar o intermediário, como "o atacadista fornece um grande número de produtos para os níveis inferiores do comércio e atividades manufatureiras" (Santos, 1979, p. 132). Nesse sentido, o atacadista ${ }^{10}$ é um dos elos entre os circuitos, que no caso da cidade de Guajará-Mirim inclui-se o fator de uso de incentivos e isenções fiscais apropriadas pelos atacadistas para propiciar um deslocamento das mercadorias para a fronteira e não serem consumidas inteiramente naquele lugar, sendo destinadas para as demais cidades rondonienses.

As atividades de transporte "desempenha dois papéis distintos, embora o mesmo veículo passa a servir sucessivamente a esses dois papéis". Em um, ele pode transportar os bens e estabelecer o elo entre as atividades e entre a indústria e o comércio, e numa outra escala ele pode ser um comerciante (Santos, 1979, p. 132), até porque os caminhões transportam cargas fracionadas em suas carroceiras, ou seja, numa mesma viagem pode deslocar bens que vão atender o circuito superior/empresas e inferior/comerciantes.

Em um esquema (figura 8) adaptado de Santos (1979) podemos visualizar algumas atividades e como estão situadas dentro de cada circuito.

10 "Os atacadistas e transportadores têm atividades do tipo mistas, pelo fato de sua dupla ligação. Ambos têm laços funcionais tanto com o circuito superior como com o circuito inferior da economia urbana e regional. O atacadista está no topo de uma cadeia decrescente de intermediários, que chega frequentemente ao nível do "feirante" ou do simples vendedor ambulante" (Santos, 2004, p. 41). 
Thiago Oliveira Neto, Ricardo José Batista Nogueira, Carlos Eduardo Silva Simões Rafael, Yuji Santos Yano Comércio em fronteira: os circuitos da economia urbana em Guajará-Mirim (Estado de Rondônia, Brasil) e Guayaramerín (Departamento de Beni, Bolívia)

Figura 8. O circuito superior e inferior da economia urbana.

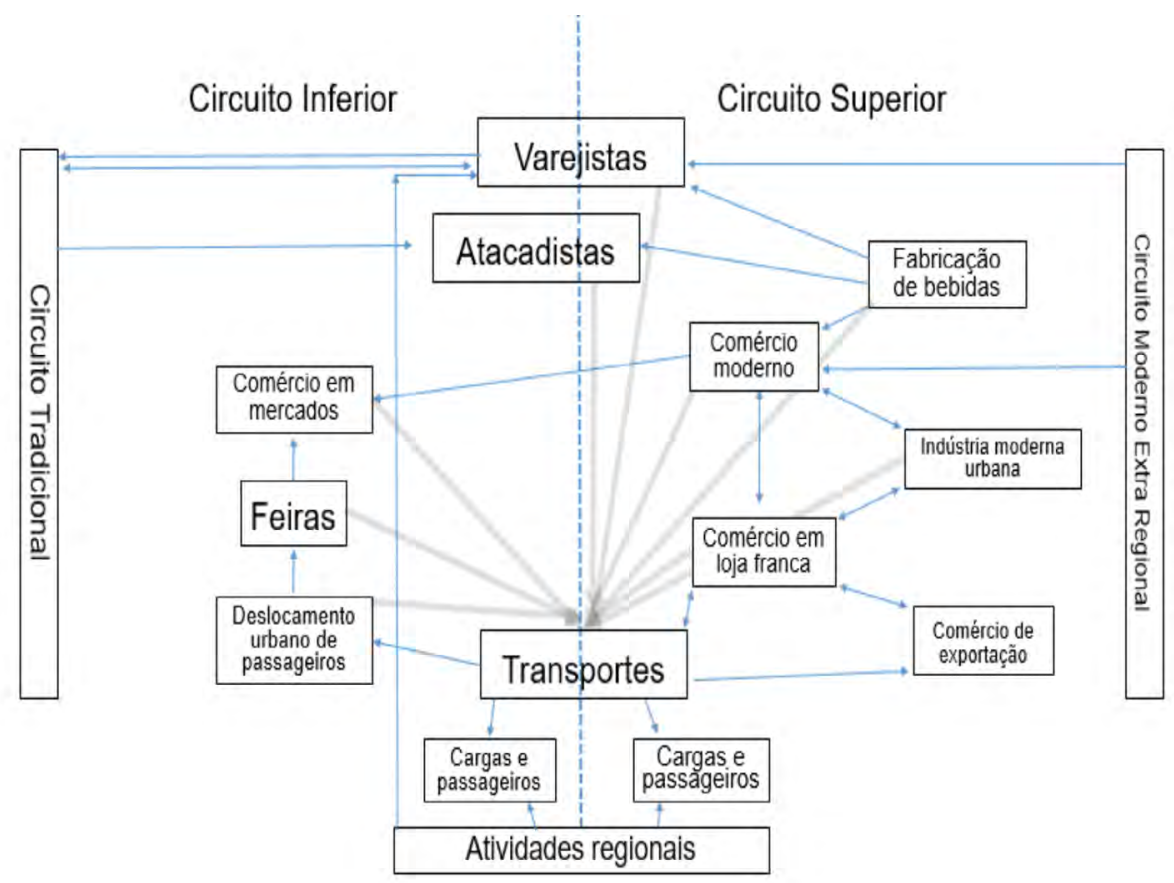

Adaptado de Santos (1979, p. 133; 2004, p. 40).

Santos já chamava a atenção que essa proposta não constituía numa “definição rígida" (1979, p. 134; 2004, p. 42). Nesse sentido, cada circuito pode ser definido por um conjunto de atividades (quadro 1).

O que está presente em ambos os circuitos são: o trabalho, fluxo de pessoas, mercadorias, veículos e grandes sistemas de engenharia que foram a base para os deslocamentos entre a fronteira com os centros de produção e de comercialização de bens de consumo. Ainda mais:

Existe, no entanto, uma complementaridade hierárquica e complexa quando o pequeno comércio ou mesmo os vendedores ambulantes escoam os bens que sobejam da economia superior ou no momento em que as redes globais e nacionais chegam às áreas periféricas e acabam diminuindo o tamanho dos mercados do circuito inferior (Silveira, 2015, p. 256).

No que se refere a movimentação de mercadorias, pode-se apontar que "as atividades do sistema de fluxos superior manipulam grandes 
Thiago Oliveira Neto, Ricardo José Batista Nogueira, Carlos Eduardo Silva Simões Rafael, Yuji Santos Yano

Comércio em fronteira: os circuitos da economia urbana em Guajará-Mirim (Estado de Rondônia, Brasil) e Guayaramerín (Departamento de Beni, Bolívia)

Quadro 1. Diferenciações entre os circuitos por meio das atividades

\begin{tabular}{|c|c|c|}
\hline Atividades & Circuito superior & Circuito inferior \\
\hline Tecnologia & Capital intensivo & Trabalho intensivo \\
\hline Cartão de credito & Possui & Possui \\
\hline Organização & Burocrática & Rudimentar \\
\hline Trabalho & Limitado & Abundante \\
\hline Remuneração & Regular & - \\
\hline Balanços & Grandes & Pequenas quantidades \\
\hline Preços & Fixados & Negociável com o vendedor \\
\hline Relações com a clientela & impessoal & Direta \\
\hline Custos fixos & Instalações de grande & $\begin{array}{c}\text { Instalações de médio e peque- } \\
\text { no porte, ás vezes sem fixar } \\
\text { capital. }\end{array}$ \\
\hline Publicidade & Sim & Sim \\
\hline Grande Capital & Sim & Não \\
\hline Ajuda governamental & $\begin{array}{c}\text { Sim, via redução e } \\
\text { isenções de impostos }\end{array}$ & Não. \\
\hline Loja Franca & Sim & Classe média e baixa \\
\hline Consumo & Classe média &
\end{tabular}

Adaptado e modificado de Santos (1979, p. 136).

quantidades de bens, enquanto as do sistema inferior, no comércio (...) trabalham com pequenas quantidades" (Santos, 1979, p. 137) que no caso do inferior, as cargas são deslocadas de forma fracionada, ao invés do circuito superior em que um veículo desloca muita das vezes um conjunto de bens inteiramente para um único atacadista.

A circulação entre esses centros se expressa pela configuração constituída entre as cidades de produção ou de revenda-transporte-cidades de fronteira, sendo que essa configuração ainda pode se desdobrar em mais duas particularidades que envolvem os transportes, primeiro pelo deslocamento entre as cidades centrais com a fronteira por meio de deslocamento de cargas em caminhões/carretas com o transporte de toneladas de cargas e que foram adquiridas por alguma empresa, num segundo aspecto o transporte ocorre não somente com o uso de caminhões, mas com o uso de ônibus em que as pessoas viajam e colocam nos bagageiros do veículo as encomendas feitas pelos comércios fronteiriços. 
Os transportes assumem um papel relevante para a circulação de bens de consumo de ambos os circuitos espaciais, em todo caso, não somente o transporte rodoviário possibilita essa circulação, principalmente no que tange sobre uma parte da Amazônia, os deslocamentos são realizados essencialmente pela via fluvial onde as embarcações assumem o elo central das atividades comerciais. Nas cidades que são conectadas pelos rios e rodovias, ambos passam a ser relevantes, um acaba tendo um predomínio na circulação como é o caso das rodovias e aumentando a primazia desta quando a mesma é asfaltada e os deslocamentos entre os lugares são feitos em intervalos de tempo inferiores do que pela via fluvial.

No caso da fronteira onde estão as cidades de Guajará-Mirim e Guayaramerín, os deslocamentos rodoviários e fluviais são relevantes, principalmente para a cidade boliviana em decorrência da malha rodoviária ser inconclusa entre os centros econômicos e políticos -Trinidad, Santa Cruz, La Paz- até a fronteira.

No que tange ao circuito superior, o que chamou atenção foi a existência de grandes galpões e empresas que se apropriaram da legislação de incentivos fiscais para realizar a compra de bens de consumo e destinar em primeiro plano as compras para a cidade de Guajará-Mirim e posteriormente reenviar as cargas para outras cidades de Rondônia, ou seja, os empresários aproveitaram das isenções para comprar bens para revender em outros lugares ao invés de serem consumidas na fronteira.

Uma parte substancial dos fluxos de caminhões e carretas na cidade de Guajará-Mirim é constituído do deslocamento de cargas diversas que são destinadas para a cidade, e ao chegarem, os veículos apresentam as notas ficais nos postos da Receita Federal e da Suframa, às vezes vão até um determinado lugar da cidade onde tem uma unidade da empresa -galpão- e posteriormente, por vezes sem fazer transbordo de cargas, os veículos retornam com as cargas para as demais cidades rondonienses, aproveitando-se das isenções e reduções de impostos da cidade fronteiriça e não tendo o consumo das mercadorias na fronteira.

Silveira aponta que o crédito e o consumo são variáveis semelhantes aos circuitos, sendo que no circuito inferior a integração na contiguidade é dada pelas variáveis centradas na compra de insumos e a contratação de serviços na cidade, o que explica o adensamento de formas de comércio popular e as localizações próximas aos depósitos e fornecedores (2015). 
A exportação é feita por empresas transportadoras que utilizam a legislação sobre o comércio exterior e cruzam a fronteira por etapas como a passagem pelo controle aduaneiro (Benedetti; Salizzi, 2011).

A dinamicidade da fronteira ocorre em parte pela existência do comércio de fronteira. No caso de Guajará-Mirim, os atacadistas não estão diretamente vinculados a isso, pois as mercadorias destinadas para aquela cidade são retornadas para as demais cidades rondonienses, enquanto na cidade de Guayaramerín os comércios próximos da Aduana são responsáveis pela movimentação de pessoas.

A diferenciação na oferta de bens de consumo é um dos elementos que alimenta a dinamicidade da fronteira, pois se na cidade de Guayaramerín encontra-se a comercialização de vestuário, brinquedos, relógios e restaurantes que atraem brasileiros em decorrência dos preços serem inferiores no Brasil, na cidade de Guajará-Mirim a oferta de bens de consumo como arroz, carne, frango e matérias de construção civil são os elementos adquiridos pelos bolivianos que deslocam esses bens para suas cidades próximas da fronteira. Todavia, como o fluxo de brasileiros é mais frequente para o lado boliviano, é lá que encontramos os pequenos "cambistas" trocando moeda para os visitantes.

Um terceiro circuito que pode ser apontado para o caso particular da fronteira, este é constituído pelo circuito de estudantes/faculdades, formado por pessoas que cruzam a fronteira para estudar nas faculdades particulares da Bolívia ${ }^{11}$ e oferecem cursos como medicina, que possuem custos mais baratos que um curso em uma instituição privada no Brasil. Esse fluxo fortalece ainda mais as interações entre as cidades fronteiriças com o deslocamento de pessoas e de mercadorias, mesmo que seja em bagagens de mão.

O circuito das empresas e do comércio possuem uma dimensão espacial no espaço de fronteira (figura 9).

11 Um dos fluxos do cotidiano da fronteira corresponde "a capacidade dos equipamentos de Ensino Superior da Bolívia de atraírem os brasileiros" (Silva; Diniz, 2019, p. 185). 
Thiago Oliveira Neto, Ricardo José Batista Nogueira, Carlos Eduardo Silva Simões Rafael, Yuji Santos Yano Comércio em fronteira: os circuitos da economia urbana em Guajará-Mirim (Estado de Rondônia, Brasil) e Guayaramerín (Departamento de Beni, Bolívia)

Figura 9. O comércio na fronteira. Em verde o circuito dos atacadistas e em vermelho o circuito do comércio, em azul os bancos.

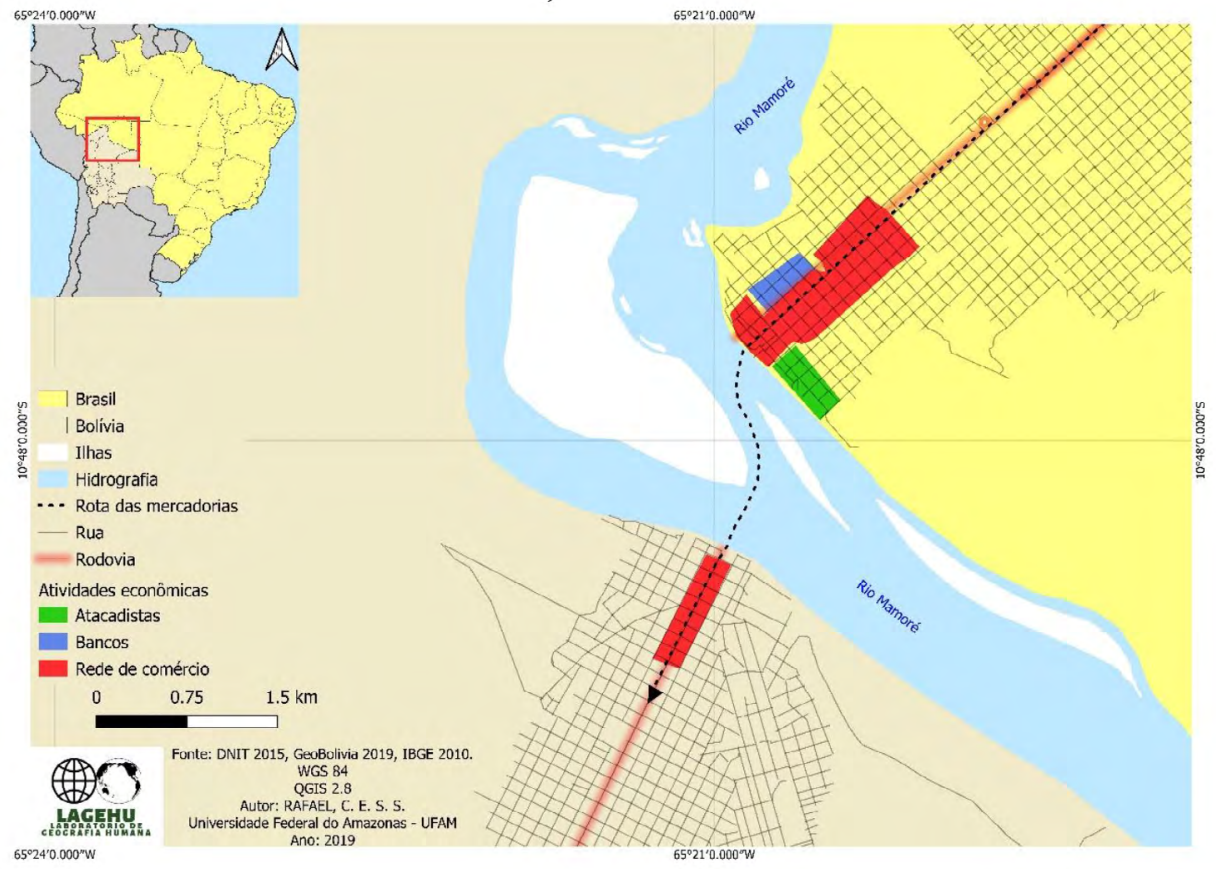

A crítica que talvez se desenhe é constituída primeiramente pela atuação do Estado na fronteira onde se induz por meio de normatizações o estabelecimento de reduções e isenções fiscais, ou seja, estimula apenas o comércio com as vendas de produtos; a segunda ressalva a ser feita é o não empenho empresarial para a montagem e a inserção de unidades de processamento na Suframa, ou seja, não se utiliza os incentivos para a industrialização.

Com esse panorama, nota-se um duplo aspecto errôneo, o incentivo por parte do Estado no comércio e o não aproveitamento dos incentivos por parte dos empresários para fins de se estabelecer uma indústria na cidade fronteiriça.

O papel do Estado na fronteira não se restringe a defesa e a fiscalização do que entra e sai do país, pode-se observar tanto nas cidades de Guajará-Mirim, Tabatinga e Oiapoque que as instituições do Estado, seja no âmbito federal, estadual e municipal representam a presença do Estado na fronteira e contribuem positivamente para as dinâmicas econômicas no 
comercio local e fronteiriço em decorrência do consumo das pessoas que moram nas cidades e dos servidores públicos e demais trabalhadores nas instituições situadas na fronteira.

No caso da cidade de Guajará-Mirim, a concentração de serviços públicos e de estabelecimentos comerciais são dois principais elementos que dinamizam a economia local. Obviamente que a própria presença de mais de meia dúzia de instituições federais e estaduais na cidade indicam claramente a presença do Estado na fronteira, seja por aqueles vinculadas à segurança -polícia federal, receita federal, exército, marinha- ou instituições como Instituto Brasileiro do Meio Ambiente e dos Recursos Naturais Renováveis-Ibama, Instituto Chico Mendes de Conservação da Biodiversidade-Icmbio, Fundação Nacional do Índio-Funai, Secretaria Especial de Saúde Indígena-Sesai, Universidade Federal de Rondônia-Unir, Instituto Federal de Rondônia-Ifro, etc., que são vinculadas a outras esferas do Estado.

Se por um lado a existência dessas instituições ajuda a fixar temporariamente pessoas e recursos na cidade, por outro lado, o Estado por meio de suas atribuições jurídicas, institui e instituiu meios para dinamizar a economia na fronteira por meio de redução e de isenção fiscal para empresários com os propósitos voltados para o comércio - grandes lojas- e indústria.

Novas transformações do ponto de vista do circuito superior podem ocorrer a partir da portaria $\mathrm{n}^{\circ} 307$, de 17 julho de 2014 e pela instrução normativa ${ }^{\circ} 1.799$, de 16 de março de $2018^{12}$ que estabelece normas complementares a portaria anterior (Brasil, 2019b) e regulamenta a autorização para o funcionamento das Lojas Francas ${ }^{13}$ no espaço de fronteira terrestre.

12 “A Instrução Normativa [Receita Federal do Brasil] RFB n 1799, de 2018, traz também, em seu art. 5, a determinação de que a autorização para concessão do regime especial de loja franca, quando feita em fronteira terrestre, seja feita à pessoa jurídica estabelecida no País que atenda a determinadas condições, dentre elas, cumprir requisitos de regularidade fiscal, não possuir pendências junto à Secretaria da Receita Federal do Brasil, ter patrimônio líquido igual ou superior a $\mathrm{R} \$ 2$ milhões de reais e dispor de sistema informatizado para controle de entrada, estoque e saída de mercadorias, de registro e apuração de créditos tributários, próprios e de terceiros, devidos, extintos ou com pagamento suspenso, integrado aos sistemas corporativos da beneficiária, que atenda aos requisitos e especificações estabelecidos em ato normativo específico da Coordenação-Geral de Administração Aduaneira (Coana), o qual é detalhado em seu art, 32" (Brasil, 2019b).

13 "O regime aduaneiro especial de loja franca, mundialmente conhecidas como Duty Free, permite a instalação de estabelecimento comercial em portos ou em aeroportos alfandegados (zona primária) para vender mercadoria nacional ou estrangeira a passageiro em viagem internacional, sem a cobrança de tributos, contra pagamento em moeda nacional ou estrangeira. No ano de 2012, foi autorizada também a instalação de lojas francas em fronteiras terrestres, em municípios caracterizados como cidades gêmeas de cidades estrangeiras na linda de fronteira do Brasil. A importação para admissão no regime é realizada em consignação, permitindo-se o pagamento ao consignante no exterior após a efetiva venda da mercadoria na loja 
Thiago Oliveira Neto, Ricardo José Batista Nogueira, Carlos Eduardo Silva Simões Rafael, Yuji Santos Yano Comércio em fronteira: os circuitos da economia urbana em Guajará-Mirim (Estado de Rondônia, Brasil) e Guayaramerín (Departamento de Beni, Bolívia)

A proposta visa a criação de espaços para a compra de mercadorias com o objetivo de dinamizar a economia local com a comercialização de mercadorias nacionais e internacionais com redução e isenções de impostos (Serpro, 2019)

Na modalidade de Loja Franca a aquisição das mercadorias ocorrerá com o limite máximo de compras com isenção no valor de US\$ 300,00 a cada intervalo de 1 mês por viajante, podendo nesse mesmo intervalo comprar no máximo: "12 litros de bebidas alcoólicas; 20 maços de cigarros; 25 unidades de charutos ou cigarrilhas; e 250 gramas de fumo preparado para cachimbo" (Brasil, 2019b, S/P).

Um dos requisitos para autorização da loja franca é possuir um sistema informatizado, ser pessoa jurídica, cumprir requisitos de regularidade fiscal, ausência de pendências à Secretaria da Receita Federal do Brasil, possuir um patrimônio com valor liquido igualou superior a $\mathrm{R} \$ 2$ milhões de reais, integração de sistemas etc. (Brasil, 2019b). Ou seja, foi uma estrutura normativa pensada para atender apenas as empresas do circuito superior da economia urbana na fronteira, inviabilizando muita das vezes a instalação de um empreendimento com essas características com capital local, favorecendo a expansão e a instalação de empresas exógenas aquele lugar de fronteira.

\section{Considerações finais}

A circulação e o comércio na fronteira permitem compreender os arranjos espaciais formados nas fronteiras e como cada lugar é uma combinação de arranjos existentes com aspectos comuns, o que torna singular, ao mesmo tempo, elementos do cotidiano da fronteira como a circulação de pessoas e de mercadorias é um elemento geral, ou seja, recorrente do próprio espaço de fronteira.

A adaptação da teoria de Santos $(1979 ; 2004)$ em circuito dos atacadistas e comerciantes teve como propósito elucidar uma parte das atividades comerciais naquela fronteira. Além desse aspecto, pode-se observar a existência de um circuito constituído pelos fluxos de estudantes

franca. As mercadorias importadas pelos consignatários das lojas franças permanecerão com suspensão do pagamento dos tributos até a sua venda. Após a comercialização das mercadorias, a suspensão será convertida em isenção" (Brasil, 2019a, S/P). 
Thiago Oliveira Neto, Ricardo José Batista Nogueira, Carlos Eduardo Silva Simões Rafael, Yuji Santos Yano Comércio em fronteira: os circuitos da economia urbana em Guajará-Mirim (Estado de Rondônia, Brasil) e Guayaramerín (Departamento de Beni, Bolivia)

constituídos de brasileiros que atravessam a fronteira para cursar medicina nas faculdades particulares da Bolívia.

Um dos elementos da dinamicidade da fronteira em Guajará-Mirim é o artifício criado pelos incentivos fiscais para área de livre comércio com a presença de galpões que recebem as mercadorias de várias regiões do Brasil e reenviam para as demais cidades rondonienses sem ser consumidas no comércio local do espaço de fronteira, tendo apenas um aproveitamento das leis para benefício das empresas atacadistas. Ou seja, na verdade a dinâmica nesta fronteira não é dada essencialmente pela condição locacional de ser fronteira, mas a criação de uma legislação para beneficiar a condição fronteiriça é apropriada por comerciantes que conseguem escapar à tributação quando fazer suas mercadorias apenas circular na área de livre comércio, não sendo aí o seu destino final. Para ficar mais claro: a fronteira de Guajará-Mirim beneficia mais quem está no restante do Estado de Rondônia, do que propriamente a cidade de fronteira.

Outro elemento é formado pela presença de várias instituições do Estado, tanto na cidade de Guayaramerín quanto em Guajará-Mirim, principalmente as instituições militares em ambas, e no caso da cidade brasileira nota-se a presença de instituições que estão vinculadas ao ensino técnico, superior e a proteção ambiental e dos povos indígenas. Essas instituições formadas por recursos humanos fazem parte do espaço de fronteira e parte de suas realizações, como compras, refeições etc., que lá ocorrem, contribuindo para dinamicidade econômica na fronteira.

\section{Agradecimentos:}

Pelo financiamento do CNPq referente ao projeto: Dinâmica da zona de fronteira Brasil-Bolívia; Aruanã Transportes pela cortesia no deslocamento rodoviário de Manaus-Humaitá-Manaus; Martha Sena pelo apoio a estadia na cidade de Porto Velho; Isa Raulino pela revisão dos textos; Ginneth Gómez pela revisão e tradução do resumo. 
Thiago Oliveira Neto, Ricardo José Batista Nogueira, Carlos Eduardo Silva Simões Rafael, Yuji Santos Yano Comércio em fronteira: os circuitos da economia urbana em Guajará-Mirim (Estado de Rondônia, Brasil) e Guayaramerín (Departamento de Beni, Bolívia)

\section{Referências}

Benedetti, A. y Salizzi, E. (2011). Frontera y movilidad aproximaciones al caso Argentino-Boliviano. Revista do Centro de Educação e Letras, v. $13, \mathrm{n}^{\circ} 1$, pp. $55-80$.

Benedetti, A. (2014). Espacios fronterizos del sur sudamericano. Propuesta de un modelo conceptual para su estudio. Estudios Fronterizos, Nueva Época, vol. 15, núm. 29, pp. 11- 47.

Brasil. (2019a). Lojas Francas. Receita Federal. Recuperado: $\quad$ http://receita.economia.gov.br/orientacao/aduaneira/regimes-e-controles-especiais/regimes-aduaneiros-especiais/ loja-franca

Brasil. (2019b) Receita Federal publica norma referente às lojas francas de fronteira. Receita. Federal. Recuperado: http://receita.economia. gov.br/noticias/ascom/2018/marco/receita-federal-publica-normareferente-as-lojas-francas-de-fronteira

Instituto Brasileiro de Geografia e Estatistica - IBGE. (2019a). Guajará-Mirim. Recuperado: https://cidades.ibge.gov.br/brasil/ro/ guajara-mirim/panorama

Instituto Brasileiro de Geografia e Estatistica - IBGE. (2019b). Nova Mamoré. Recuperado: https://cidades.ibge.gov.br/brasil/ro/nova-mamore/ panorama

Instituto Nacional de Estadística INE. (2019). 63,0\% de la población del Beni se encuentra entre los 0 y 28 años. 18/11/2016. Recuperado: https://www.ine.gob.bo/index.php/prensa/notas-de-prensa/ item/442-63-0-de-la-poblacion-del-beni-se-encuentra-entre-los-0-y28-anos

Lira, J. (2017). Mobilidade espacial na fronteira e a formação de espaço de vida Amazônico: o caso das cidades gêmeas de Guajará Mirim (Brasil) e Guayaramerín (Bolívia). Geografares, n² 24, pp. 118-131.

Moraes, A. C. R. (2000). Capitalismo, Geografia e Meio Ambiente. Tese de Livre Docência em Geografia, Departamento de Geografia, Universidade de São Paulo. Brasil. (pp. 201)

Santos, M. (1979). Espaço e sociedade: ensaios. Petrópolis: Vozes.

Santos, M. (2004). O espaço dividido: os dois circuitos da economia urbana dos países subdesenvolvidos. $2^{\circ}$ ed. São Paulo: Edusp. 
Thiago Oliveira Neto, Ricardo José Batista Nogueira, Carlos Eduardo Silva Simões Rafael, Yuji Santos Yano Comércio em fronteira: os circuitos da economia urbana em Guajará-Mirim (Estado de Rondônia, Brasil) e Guayaramerín (Departamento de Beni, Bolívia)

Serviço Federal de Processamento de Dados - SERPRO. (2019). Lojas Francas vão dinamizar economia de cidade de fronteiras. Recuperado: https://www.serpro.gov.br/menu/noticias/noticias-2019/ lojas-francas-dinamizam-economia-cidades-fronteira

Silva, L. L. S. da y Diniz, A. M. A. (2019). Estereótipos transfronteiriços: olhares entrecruzados de bolivianos e brasileiros das cidades-gêmeas de Guajará-Mirim (Bra) e Guayaramerín (Bol). Geografia em Questão, v. 12, n 2, pp. 176-203.

Silva, G. de V. (2013). Desenvolvimento econômico em cidades da fronteira amazônica: ações, escalas e recursos para Oiapoque-AP. Confins, v. 17, S/P.

Silveira, M. L. (2015). Modernização contemporânea e nova constituição dos circuitos da economia urbana. Geousp-Espaço e Tempo, v. 19, $\mathrm{n}^{\circ} 2$, pp. 246-262. 